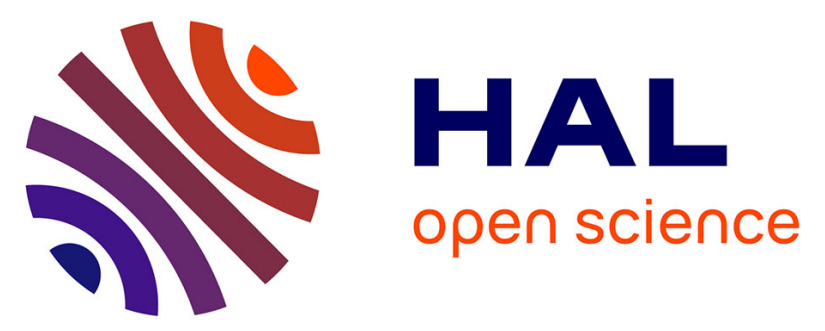

\title{
DEM error retrieval by analyzing time series of differential interferograms
}

Lionel Bombrun, Michel Gay, Emmanuel Trouvé, Gabriel Vasile, Jerome I. Mars

\section{- To cite this version:}

Lionel Bombrun, Michel Gay, Emmanuel Trouvé, Gabriel Vasile, Jerome I. Mars. DEM error retrieval by analyzing time series of differential interferograms. IEEE Geoscience and Remote Sensing Letters, 2009, 6 (4), pp.830-834. 10.1109/LGRS.2009.2026434 . hal-00441633

\section{HAL Id: hal-00441633 \\ https://hal.science/hal-00441633}

Submitted on 16 Dec 2009

HAL is a multi-disciplinary open access archive for the deposit and dissemination of scientific research documents, whether they are published or not. The documents may come from teaching and research institutions in France or abroad, or from public or private research centers.
L'archive ouverte pluridisciplinaire HAL, est destinée au dépôt et à la diffusion de documents scientifiques de niveau recherche, publiés ou non, émanant des établissements d'enseignement et de recherche français ou étrangers, des laboratoires publics ou privés. 


\title{
DEM Error Retrieval by Analyzing Time Series of Differential Interferograms
}

\author{
Lionel Bombrun, Member, IEEE, Michel Gay, Emmanuel Trouvé, Member, IEEE, \\ Gabriel Vasile, Member, IEEE, and Jérôme Mars, Member, IEEE
}

\begin{abstract}
Two-pass differential synthetic aperture radar interferometry processing have been successfully used by the scientific community to derive velocity fields. Nevertheless, a precise digital elevation model (DEM) is necessary to remove the topographic component from the interferograms. This letter presents a novel method to detect and retrieve DEM errors by analyzing time series of differential interferograms. The principle of the method is based on the comparison of fringe patterns with the perpendicular baseline. First, a mathematical description of the algorithm is exposed. Then, the algorithm is applied on a series of four one-day European Remote Sensing 1 and 2 satellite (ERS-1/2) interferograms.
\end{abstract}

Index Terms-Digital elevation model (DEM), interferogram time series, synthetic aperture radar (SAR) interferometry (InSAR).

\section{INTRODUCTION}

$\mathbf{S}$ YNTHETIC aperture radar (SAR) interferometry (InSAR) is widely used to create high-resolution and highaccuracy topographic maps [1], [2] and to derive velocity fields [3]-[6]. The interferometric phase is sensitive to different contributions, such as the topography, the atmospheric perturbations, and the ground displacement between the two acquisitions. The latter can be estimated by InSAR techniques if and only if nondisplacement terms can be compensated or neglected.

In two-pass differential SAR interferometry (D-InSAR), a digital elevation model (DEM) is introduced in the processing to remove the topographic component from the interferograms. When the DEM is not precise enough, residual topographic fringe patterns appear and can be misinterpreted or confused with the sought-after displacement fields. This may happen for instance when studying Alpine glacier displacement, since DEMs derived from optical data need correction in snow covered areas and Shuttle Radar Topography Mission DEM is

Manuscript received February 14, 2008; revised June 13, 2008, November 7, 2008, February 27, 2009, and June 8, 2009. First published August 28, 2009; current version published October 14, 2009. This work was supported by the MEGATOR and EFIDIR projects (ACI-MD-04 and ANR-2007-MDCO-04).

L. Bombrun, M. Gay, G. Vasile, and J. Mars are with the GIPSA Laboratory, Grenoble Institute of Technology, 38031 Grenoble, France (e-mail: lionel.bombrun@gipsa-lab.grenoble-inp.fr; michel.gay @ gipsa-lab.grenobleinp.fr; gabriel.vasile@gipsa-lab.grenoble-inp.fr; jerome.mars@gipsa-lab. grenoble-inp.fr).

E. Trouvé is with the Laboratoire d'Informatique, Systèmes, Traitement de l'Information et de la Connaissance, 74016 Annecy, France (e-mail: emmanuel.trouve@univ-savoie.fr).

Color versions of one or more of the figures in this paper are available online at http://ieeexplore.iee.org.

Digital Object Identifier 10.1109/LGRS.2009.2026434 interpolated in shadow areas. When no DEM is available to compensate the topographic phase, an alternative consists in using only SAR interferometric data with three or four acquisitions. In the so-called "four-pass method," two independent interferograms are computed and combined according to their baselines to remove the topographic fringes.

In this letter, a different strategy based on the same principle is proposed to detect and retrieve DEM errors by analyzing time series of differential interferograms. The proposed method is dedicated to the analysis of time series of differential interferograms computed with the available DEM. It consists in computing the phase differences between differential interferograms and comparing the resulting fringe patterns with the perpendicular baseline differences. A test is applied in order to discriminate residual topographic fringes due to DEM errors from fringes due to the evolution of the displacement field between the interferograms or other error sources. If residual fringes vary with the perpendicular baselines, they are identified as topographic error fringes. In this case, an estimation of the DEM errors can be performed followed by DEM corrections. Otherwise, if the other error sources can be neglected (mainly tropospheric effects), the residual fringes reveal a variation of the displacement field which provides useful information on the studied area.

In the following sections, some definitions and a description of the proposed method are first provided. Then, the experimental results are presented on a series of European Remote Sensing 1 and 2 (ERS-1/2) satellite interferograms acquired in the Alps to study glacier displacement fields in Chamonix Mont-Blanc area.

\section{Methodology}

\section{A. Mathematical Considerations}

Let us denote by $\Phi^{i}$ a tandem interferogram acquired at date $(i, i+1) . \Phi_{\text {topo }}^{i}$ represents the interferometric component at date $i$ corresponding to topographic fringes, i.e., fringes due to the true height variation $\Delta z$ over the studied area. To take DEM errors into account, $\Delta z$ is expressed as the sum of the height given by the DEM $\left(\Delta z^{\mathrm{DEM}}\right)$ and the DEM error $\left(\Delta z^{\mathrm{err}}\right)$

$$
\Delta z=\Delta z^{\mathrm{DEM}}+\Delta z^{\mathrm{err}} .
$$

$\Phi_{\text {topo }}^{i}$ can be expressed as a function of the perpendicular baseline at date $i\left(B_{\perp}^{i}\right)$ by the following equation as:

$$
\Phi_{\text {topo }}^{i}=\frac{4 \pi}{\lambda} \frac{B_{\perp}^{i}}{R_{1} \sin \theta} \Delta z=\frac{2 \pi}{e_{a}^{i}} \Delta z
$$


with the height of ambiguity defined as

$$
e_{a}^{i}=\frac{\lambda}{2} \frac{R_{1} \sin \theta}{B_{\perp}^{i}}
$$

By combining (1) and (2), the topographic component can be expressed as the sum of two terms by

$$
\begin{aligned}
\Phi_{\text {topo }}^{i} & =\frac{4 \pi}{\lambda} \frac{B_{\perp}^{i}}{R_{1} \sin \theta} \Delta z^{\mathrm{DEM}}+\frac{4 \pi}{\lambda} \frac{B_{\perp}^{i}}{R_{1} \sin \theta} \Delta z^{\mathrm{err}} \\
& =\Phi_{\text {topo }}^{i, \text { DEM }}+\Phi_{\text {topo }}^{i, \text { err }}
\end{aligned}
$$

where $\Phi_{\text {topo }}^{i, \text { DEM }}$ represents the topographic component compensated by the DEM and $\Phi_{\text {topo }}^{i, \text { err }}$ is defined as residual topographic fringes, i.e., topographic fringes which are not removed from the interferogram by using the DEM.

The differential interferometric phase (named $\Phi_{\mathrm{d}}^{i}$ ) is defined as the tandem interferogram acquired at date $(i, i+1)$ minus the topographic component compensated by the DEM. $\Phi_{\mathrm{d}}^{i}$ can be expressed as follows:

$$
\Phi_{\mathrm{d}}^{i}=\Phi^{i}-\Phi_{\text {topo }}^{i, \text { DEM }}
$$

Let $\rho_{\mathrm{d}}^{i}$ and $\rho_{\mathrm{d}}^{j}$ be two differential interferograms acquired at date $(i, i+1)$ and $(j, j+1)$. The interferogram difference (noted $\rho^{i j}$ ) is defined as the Hermitian product between the two differential interferograms by

$$
\begin{aligned}
\rho^{i j} & =\rho_{\mathrm{d}}^{i} \rho_{\mathrm{d}}^{j \dagger}=c^{i} c^{j} e^{i\left(\Phi_{\mathrm{d}}^{i}-\Phi_{\mathrm{d}}^{j}\right)} \\
& =c^{i j} e^{i \Delta \Phi^{i-j}}
\end{aligned}
$$

where $c^{i j}$ is defined as the equivalent coherence.

The phase difference between differential interferograms $\Delta \Phi^{i-j}$ is defined in (9) as the difference between tandem differential interferograms phases acquired at dates $(i, i+1)$ and $(j, j+1)$

$$
\Delta \Phi^{i-j}=\operatorname{Arg}\left(\rho^{i j}\right)=\left[\Phi_{\mathrm{d}}^{i}-\Phi_{\mathrm{d}}^{j}\right] \text { modulo } 2 \pi .
$$

The phase difference between differential interferograms can be expressed as the sum of four terms as

$$
\Delta \Phi^{I-j}=\Delta \Phi_{\text {topo }}^{i j}+\Delta \Phi_{\text {atm }}^{i j}+\Delta \Phi_{\text {displ }}^{i j}+\Delta \Phi_{\text {noise }}^{i j}
$$

where $\Delta \Phi_{\text {topo }}^{i j}$ characterizes the residual topographic fringes, $\Delta \Phi_{\mathrm{atm}}^{i j}$ is the residual phase due to atmospheric artifacts, $\Delta \Phi_{\text {displ }}^{i j}$ is the component due to variations of the displacement field between the two interferograms, and $\Delta \Phi_{\text {noise }}^{i j}$ is a term of residual noise, due, for example, to temporal decorrelation.

In this letter, $\Delta \Phi_{\text {topo }}^{i j}$ is considered as the "signal part." All other terms can be viewed as the "noise part." Let us now focus on the topographic term.

1) Characterization of the "Signal Part": The residual topographic fringes $\Delta \Phi_{\text {topo }}^{i j}$ in the phase difference between interferograms at dates $i$ and $j$ can be expressed as a function of the DEM error $\Delta z^{\text {err }}$ by

$$
\begin{aligned}
\Delta \Phi_{\mathrm{topo}}^{i j} & =\left(\Phi_{\mathrm{topo}}^{i}-\Phi_{\mathrm{topo}}^{i, \text { DEM }}\right)-\left(\Phi_{\mathrm{topo}}^{j}-\Phi_{\mathrm{topo}}^{j, \mathrm{DEM}}\right) \\
& =\frac{4 \pi}{\lambda} \frac{\left(B_{\perp}^{i}-B_{\perp}^{j}\right)}{R_{1} \sin \theta} \Delta z^{\mathrm{err}} \\
& =\frac{4 \pi}{\lambda} \frac{\Delta B_{\perp}^{i j}}{R_{1} \sin \theta} \Delta z^{\mathrm{err}} \\
& =\frac{2 \pi}{\Delta e_{a}^{i j}} \Delta z^{\mathrm{err}}
\end{aligned}
$$

where the equivalent perpendicular baseline $\Delta B_{\perp}^{i j}$ can be defined as the difference of the two perpendicular baseline at dates $i$ and $j$. Similarly, the equivalent height of ambiguity $\Delta e_{a}^{i j}$ can be defined by (14)

$$
\begin{aligned}
\Delta B_{\perp}^{i j} & =B_{\perp}^{i}-B_{\perp}^{j} \\
\Delta e_{a}^{i j} & =\frac{\lambda}{2} \frac{R_{1} \sin \theta}{B_{\perp}^{i}-B_{\perp}^{j}}=\frac{1}{\frac{1}{e_{a}^{i}}-\frac{1}{e_{a}^{j}}} .
\end{aligned}
$$

Let $\Delta N_{\text {topo }}^{i j}(X, Y)$ be the number of fringes observed on $\Delta \Phi_{\text {topo }}^{i j}$ between two points $X$ and $Y$, and $\Delta z^{\operatorname{err}}(X, Y)$ the elevation error between $X$ and $Y$ points. It yields

$$
\Delta \Phi_{\text {topo }}^{i j}(X, Y)=2 \pi \Delta N_{\text {topo }}^{i j}(X, Y)
$$

and by combining (12) and (15) to

$$
\Delta z^{\mathrm{err}}(X, Y)=\Delta N_{\mathrm{topo}}^{i j}(X, Y) \Delta e_{a}^{i j} .
$$

In (16), it is interesting to note that for residual topographic fringes, the product $\Delta N_{\text {topo }}^{i j}(X, Y) \Delta e_{a}^{i j}$ is constant over the different interferogram pairs $(i, j)$. The principle of the proposed method is to test the equality from (16) over all the differential interferogram pairs of the stack in order to detect DEM errors.

2) Hypothesis Test: For real data, let $\Delta N^{i j}(X, Y)$ be the number of fringes observed on $\Delta \Phi^{i-j}$ between $X$ and $Y$ points. $\Delta N^{i j}(X, Y)$ can be expressed as the sum of two terms, one due to the topography $\Delta N_{\text {topo }}^{i j}(X, Y)$ ("signal part") and one due to other contributions (displacement fringes, atmospheric perturbations, ...) $\Delta N_{\text {other }}^{i j}(X, Y)$ ("noise part")

$$
\Delta N^{i j}(X, Y)=\Delta N_{\text {topo }}^{i j}(X, Y)+\Delta N_{\text {other }}^{i j}(X, Y) .
$$

As $\Delta N_{\text {other }}^{i j}(X, Y)$ is not inversely proportional to the equivalent height of ambiguity $\Delta e_{a}^{i j}$, one can test if the product $\Delta N^{i j}(X, Y) \Delta e_{a}^{i j}$ is constant over the different interferograms pairs $(i, j)$. This leads to the following hypothesis test:

$$
\begin{cases}H_{0}: \forall(i j) & \Delta N_{i j}(X, Y) \Delta e_{a}^{i j}=K(X, Y) \\ H_{1}: \exists(i j) & \Delta N_{i j}(X, Y) \Delta e_{a}^{i j} \neq K(X, Y) .\end{cases}
$$

1) If the first hypothesis $H_{0}$ is decided, $K(X, Y)$ is considered as a constant over all the interferograms pairs $(i, j)$. Equation (16) implies that the DEM used to remove topographic phase contribution has error. In that case, (12) allows one to estimate the DEM error $\left(\mathrm{DEM}_{\text {error }}^{i}\right)$ for the 
interferogram difference at date $i$ and $j$. This estimation is performed for all the interferograms differences. The DEM error map is the average value of the DEM error found for all the interferograms differences

$$
\mathrm{DEM}_{\text {error }}=\frac{1}{N} \sum_{i=1}^{N} \mathrm{DEM}_{\text {error }}^{i} .
$$

The new DEM is equal to the old DEM plus the DEM $_{\text {error }}$.

2) If $H_{0}$ is rejected, $K(X, Y)$ cannot be considered as a constant over all the interferograms pairs $(i, j)$. Residual fringes are not only due to DEM error.

\section{B. Comparison With the Four-Pass InSAR Method}

The conventional four-pass D-InSAR method [7] uses four independent SAR acquisitions to derive displacement measures. This method does not require a priori DEM knowledge. The first two interferometric SAR acquisitions are used to compute the topographic phase component in each pixels of the interferograms. Then, this information is used to remove topography from the second interferogram which is generated from the last two acquisitions.

In the two-pass D-InSAR method, a DEM is introduced to remove the topographic phase. This processing can be repeated to each couple of interferometric SAR acquisitions to derive a stack of two-pass differential interferograms. The proposed approach presents a novel method to a posteriori evaluate the DEM accuracy over the interferogram stack. Based on the fourpass D-InSAR principles, the height error is expressed in terms of the equivalent height of ambiguity for each interferogram. Then, the DEM anomalies are detected by the basic hypothesis testing from (18).

One can notice that the phase measured in (7) corresponds to a double interferogram differentiation. This stage is similar to the double differential proposed by the four-pass InSAR method to remove topography. However, both the data set and the context are different between the two techniques.

1) The four-pass InSAR method uses two interferograms (therefore four independent SAR acquisitions) to isolate the topographic phase [8]. This method is applied when no DEM are available to compensate the topographic phase for displacement measures.

2) In the proposed method, a series of differential interferograms is analyzed. This stack is obtained with the same DEM. If $N$ independent differential interferograms are generated, $N-1$ independent phase difference between differential interferograms are obtained. To test the hypothesis $H_{0}$, at least two independent phase difference between differential interferograms $\left(\Delta \Phi^{i-j}\right)$ are necessary. It means that the proposed method requires at least three independent differential interferograms.

The proposed method can be viewed as an extension of the four-pass InSAR method to retrieve DEM error in a series of differential interferograms.
TABLE I

PERPENDiCUlar Baseline AND Height of Ambiguity

\begin{tabular}{|c|c|c|}
\hline interferogram date & $B_{\perp}(\mathrm{m})$ & $e_{a}(\mathrm{~m})$ \\
\hline $95.10 .22 / 95.10 .23$ & -107 & 80 \\
\hline $95.12 .31 / 96.01 .01$ & 208 & 41 \\
\hline $96.03 .10 / 96.03 .11$ & 9 & 960 \\
\hline $96.04 .14 / 96.04 .15$ & 93 & 93 \\
\hline
\end{tabular}

TABLE II

EQUIVALENT PERPENDICULAR BASELINE AND EQUIVALENT HEIGHT OF AMBIGUITY

\begin{tabular}{|c|c|c|c|c|c|c|}
\hline date & $\begin{array}{c}\text { Dec. } \\
\text { Oct. }\end{array}$ & $\begin{array}{c}\text { Mar. } \\
\text { Dec. }\end{array}$ & $\begin{array}{c}\text { Mar. } \\
\text { Oct. }\end{array}$ & $\begin{array}{c}\text { Apr. } \\
\text { Mar. }\end{array}$ & $\begin{array}{c}\text { Apr. } \\
\text { Dec. }\end{array}$ & $\begin{array}{c}\text { Apr. } \\
\text { Oct. }\end{array}$ \\
\hline$\Delta B_{\perp}(\mathrm{m})$ & 315 & -199 & 116 & 84 & -115 & 200 \\
\hline$\Delta e_{a}(\mathrm{~m})$ & 27 & -43 & 74 & 103 & -75 & 43 \\
\hline
\end{tabular}

\section{APPLiCATION ON ERS-1/2 INTERFEROGRAMS}

In this section, experimental results are presented using four descending one-day ERS-1/2 tandem interferometric data acquired in the Alps over the Chamonix Mont-Blanc area from October 1995 to April 1996 (Table I). This time series has been used to estimate displacement fields over glaciers [6] and to analyze fringe patterns and coherence levels [9]. In this letter, those interferograms are analyzed to determine if topographic fringes are correctly removed from the interferograms. The proposed method described in Section II is applied over the nine studied glaciers.

First of all, the four one-day ERS-1/2 tandem interferometric pairs from October 1995 to April 1996 are processed with the Repeat Orbit Interferometry Package (ROI-PAC) software from the Jet Propulsion Laboratory. This processor takes into account the precise orbits from the Delft University, The Netherlands, to remove the orbital fringes [10]. Moreover, a DEM is used by ROI-PAC software to estimate the topographic component and remove it from the interferogram. The DEM used by the SAR processor is computed by photogrammetry from airborne photographs of 1980.

Once the four differential interferograms pairs are created, the three wrapped phase difference between differential interferograms $\left(\Delta \Phi_{\text {April-March }}, \Delta \Phi_{\text {April-December }}\right.$, and $\left.\Delta \Phi_{\text {April-October }}\right)$ and the three equivalent coherence are computed according to (8) and (9). Next, over each glacier, the three wrapped phase difference between differential interferograms are unwrapped [11].

The following algorithm is applied to determine if topographic fringes are correctly removed from the differential interferograms by means of the equivalent height of ambiguity (Table II): First, for each glacier, pixels with sufficient equivalent coherence for the three couples are selected. Then, for all the selected pixels $X$ and $Y, K^{i j}(X, Y)$ is computed for the three unwrapped phase difference between differential interferograms.

1) If $K^{i j}(X, Y)$ is a constant for all the couples, the hypothesis $H_{0}$ is decided. It means that the residual fringes are topographic ones, and the studied pixel is affected to the "topographic class."

2) If $K^{i j}(X, Y)$ varies with the interferometric couple, the hypothesis $H_{0}$ is rejected. Therefore, the pixel is affected to the "nontopographic class." 


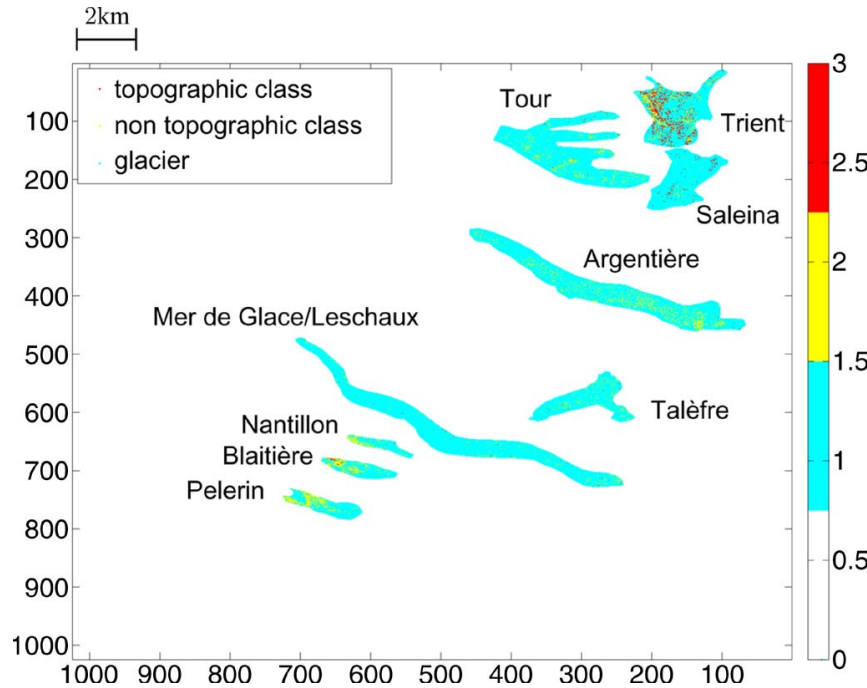

Fig. 1. Classification map into "topographic" and "nontopographic" class.
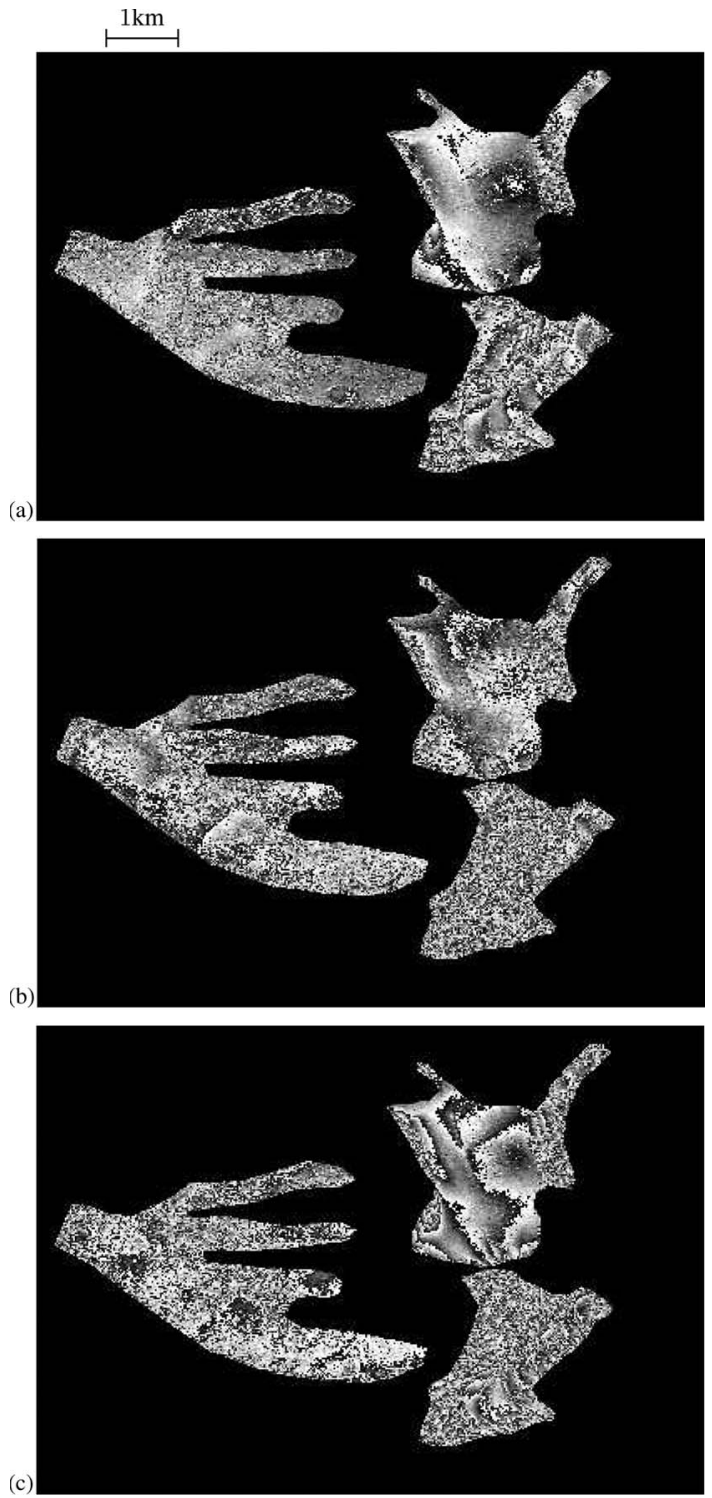

Fig. 2. Wrapped phase difference between interferograms on the Tour, Trient, and Saleina glaciers. (a) $\Delta \Phi_{\text {April-March }}$ (b) $\Delta \Phi_{\text {April-December }}$. (c) $\Delta \Phi_{\text {April-October }}$.
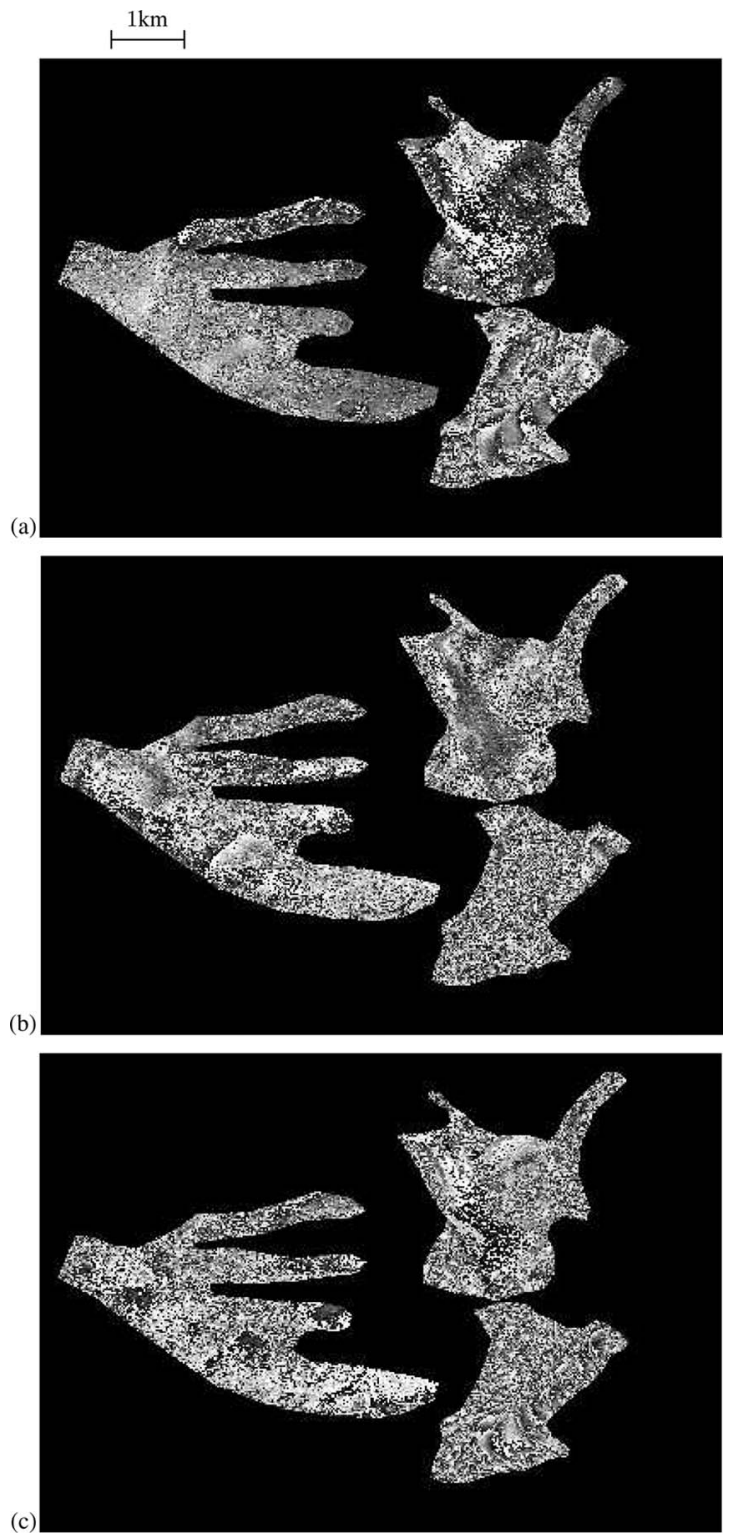

Fig. 3. Wrapped phase difference between interferograms on the Tour, Trient, and Saleina glaciers with the new DEM. (a) $\Delta \Phi_{\text {April-March }}$. (b) $\Delta \Phi_{\text {April-December }}$ (c) $\Delta \Phi_{\text {April-October }}$.

The variation coefficient $\gamma$ of the variable $K^{i j}$ is the criterion chosen to achieve this assignment. Let $\vec{K}(X, Y)$ be the vector which contains the values of $K^{i j}(X, Y)$ for all the couples $i$ and $j$ at points $X$ and $Y$. If $|\gamma(X, Y)|$ is lower than a given threshold, $K^{i j}(X, Y)$ can be said independent of the couples. The hypothesis that residual fringes are topographic ones is therefore assumed. If $|\gamma(X, Y)|$ is greater than a given threshold, the pixel is affected to the "nontopographic class."

Fig. 1 shows the result of the classification of the pixels into topographic and nontopographic class. The white color indicates nonglaciers area. Pixels in cyan are those which have not got a sufficient equivalent coherence for each couple. The proposed algorithm has not been applied on those pixels. There is not enough confidence on the interferometric phase. Pixels affected with the label "topographic class" are in red and those with the label "nontopographic class" are in yellow. 


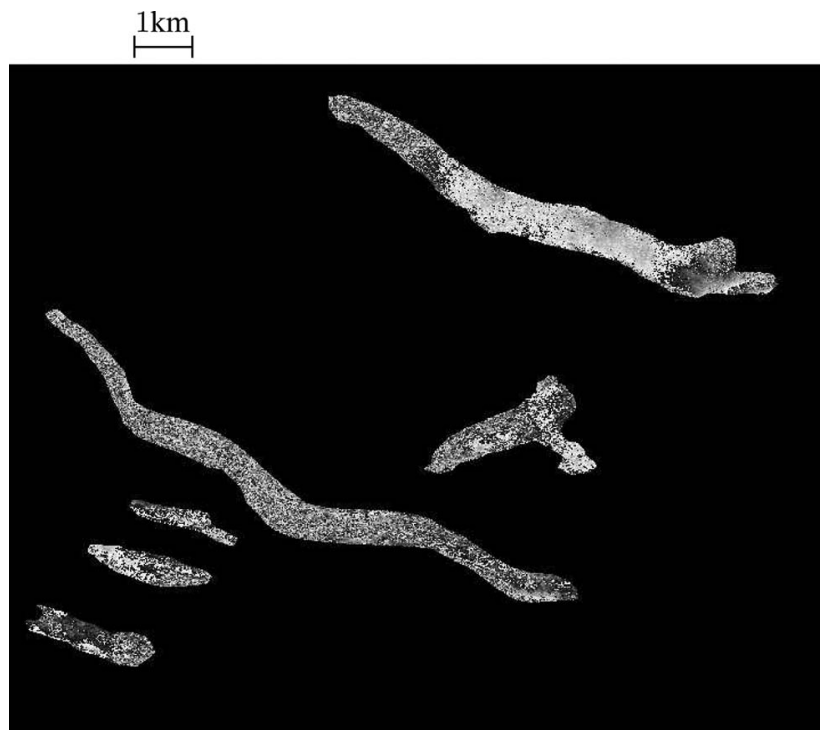

Fig. 4. Wrapped phase difference between interferograms on the Argentière glacier. $\Delta \Phi_{\text {April-October }}$.

First, it can be noticed that on most of the studied glaciers, pixels are affected to the "nontopographic class." Topographic fringes seems to be correctly removed from the interferograms and displacement profiles along those glaciers are validated.

Nevertheless, one can see on the Trient glacier located on the northeast of the image that most of the pixels are affected to the "topographic class." We can conclude that topographic fringes are not well removed on the Trient glacier probably because of the insufficient precision of the DEM on the Trient glacier which is located in Switzerland. Fig. 2 shows the wrapped phase difference between interferograms on the Tour, Trient, and Saleina glaciers. Residual fringes can be observed on the Trient glacier situated on the northeast of the image. The proposed method allows characterizing those fringes as residual topographic fringes.

To remove topographic fringes on the Trient glacier, DEM errors are first estimated according to (12). Then, topographic fringes are calculated with the corrected DEM and removed from the interferograms. Fig. 3 shows the wrapped phase difference between interferograms on the Tour, Trient, and Saleina glaciers computed with the new DEM. Now, residual fringes do not vary with the equivalent height of ambiguity. It confirms that fringes observed previously on the Trient glaciers were topographic ones.

Fig. 4 shows the wrapped phase difference between differential interferograms $\left(\Delta \Phi_{\text {April-October }}\right)$. On the Argentière glacier, located on the north of the image, residual fringes are observed. The proposed algorithm does not detect those fringes as topographic ones. Residual fringes can be due to atmospheric artifacts or to an evolution of the velocity field. The authors have shown that one-day atmospheric changes are minimal in winter [6]. Residual fringes observed on the upper part of the Argentière glacier can be interpreted as an evolution of the displacement field. Those fringes show an acceleration of the upper part of the glacier in October 1995 compared to April 1996.

\section{Conclusion}

In this letter, a novel method based on the analysis of a series of phase difference between differential interferograms was exposed to detect fringes due to DEM errors and separate them from fringes due to motion variation or atmospheric artifacts. Relations between DEM error, differential interferogram phase difference and the equivalent height of ambiguity were established. Then, an algorithm has been proposed to determine if topographic fringes are correctly removed from the interferograms. If not, DEM errors are retrieved from the differential interferogram differences. Then, interferograms are generated with the new DEM and fringes detected as topographic ones are removed. Nevertheless, it is quite difficult to quantify the DEM accuracy. Indeed, the detection of residual topographic fringes depends on the threshold value imposed during the hypothesis test, and on the possible presence of other fringe sources. If the new DEM is valid, tropospheric effects can be neglected or compensated with external data, and displacement fields variations can be studied as done on the upper part of the Argentière glacier.

\section{ACKNOWLEDGMENT}

The authors would like to thank the anonymous reviewers for providing useful comments and advice on this letter and the European Space Agency for providing ERS SAR data through the Category 1 proposals No. 1088 and 3525.

\section{REFERENCES}

[1] H. Zebker, C. Werner, P. Rosen, and S. Hensley, "Accuracy of topographics map derived from ERS-1 interferometric radar," IEEE Trans. Geosci. Remote Sens., vol. 32, no. 4, pp. 823-836, Jul. 1994.

[2] G. Rufino, A. Moccia, and S. Esposito, "DEM generation by means of ERS tandem data," IEEE Trans. Geosci. Remote Sens., vol. 36, no. 6, pp. 1905-1912, Nov. 1998.

[3] D. Massonnet and T. Rabaute, "Radar interferometry, limits and potential," IEEE Trans. Geosci. Remote Sens., vol. 31, no. 2, pp. 455-464, Mar. 1993.

[4] I. Joughin, R. Kwok, and M. Fahnestock, "Interferometric estimation of three-dimensional ice-flow using ascending and descending passes," IEEE Trans. Geosci. Remote Sens., vol. 36, no. 1, pp. 25-37, Jan. 1998.

[5] K. Mattar, P. Vachon, D. Geudtner, A. Gray, I. Cumming, and M. Brugman, "Validation of alpine glacier velocity measurements using ERS tandem-mission SAR data," IEEE Trans. Geosci. Remote Sens., vol. 36, no. 3, pp. 974-984, May 1998.

[6] E. Trouvé, G. Vasile, M. Gay, L. Bombrun, P. Grussenmeyer, T. Landes, J. Nicolas, P. Bolon, I. Petillot, A. Julea, L. Valet, J. Chanussot, and M. Koehl, "Combining airborne photographs and spaceborne SAR data to monitor temperate glaciers: Potentials and limits," IEEE Trans. Geosci. Remote Sens., vol. 45, no. 4, pp. 905-924, Apr. 2007.

[7] Z. Li, X. Li, X. Ren, and Q. Dong, "Frozen group deformation monitoring using SAR interferometry," in Proc. IGARSS, 2003, vol. 4, pp. 2933-2935.

[8] J.-F. Zhang and Q. Qin, "The research of difference interferometric SAR technique," in Proc. IGARSS, Toulouse, France, 2003, vol. 6, pp. 3827-3829.

[9] L. Bombrun, I. Pétillot, G. Vasile, M. Gay, E. Trouvé, P. Bolon, J.-M. Nicolas, and T. Landes, "Multi-date ERS tandem interferogram analysis: Application to alpine glaciers," in Proc. MULTITEMP, Leuven, Belgium, 2007.

[10] R. Scharroo and P. Visser, "Precise orbit determination and gravity field improvement for the ERS satellites," J. Geophys. Res., vol. 103, no. C4, pp. 8113-8127, Apr. 1998.

[11] E. Trouvé, J. M. Nicolas, and H. Maître, "Improving phase unwrapping techniques by the use of local frequency," IEEE Trans. Geosci. Remote Sens., vol. 36, no. 6, pp. 1963-1972, Nov. 1998. 